\title{
Regulation of Myelination in the Central Nervous System by Nuclear Lamin B1 and Non-coding RNAs
}

\author{
Shu-Ting Lin ${ }^{1}$, Mary Y Heng ${ }^{1}$, Louis J Ptáček ${ }^{1,2}$ and Ying-Hui Fu ${ }^{1 *}$
}

\begin{abstract}
Adult-onset autosomal dominant leukodystrophy (ADLD) is a progressive and fatal hereditary demyelination disorder characterized initially by autonomic dysfunction and loss of myelin in the central nervous system (CNS). Majority of ADLD is caused by a genomic duplication of the nuclear lamin B1 gene (LMNB1) encoding lamin B1 protein, resulting in increased gene dosage in brain tissue. In vitro, excessive lamin B1 at the cellular level reduces transcription of myelin genes, leading to premature arrest of oligodendrocyte differentiation. Murine models of ADLD overexpressing LMNB1 exhibited age-dependent motor deficits and myelin defects, which are associated with reduced occupancy of the Yin Yang 1 transcription factor at the promoter region of the proteolipid protein gene. Lamin B1 overexpression mediates oligodendrocyte cell-autonomous neuropathology in ADLD and suggests lamin B1 as an important regulator of myelin formation and maintenance during aging. Identification of microRNA-23 (miR-23) as a negative regulator of lamin B1 can ameliorate the consequences of excessive lamin B1 at the cellular level. miR-23a-overexpressing mice display enhanced oligodendrocyte differentiation and myelin synthesis. miR-23a targets include a protein coding transcript PTEN (phosphatase and tensin homolog on chromosome 10), and a long noncoding RNA (2700046G09Rik), indicating a unique role for miR-23a in the coordination of proteins and noncoding RNAs in generating and maintaining healthy myelin. Here, we provide a concise review of the current literature on clinical presentations of ADLD and how lamin B1 affects myelination and other developmental processes. Moreover, we address the emerging role of non-coding RNAs (ncRNAs) in modulating gene networks, specifically investigating miR-23 as a potential target for the treatment of ADLD and other demyelinating disorders.
\end{abstract}

Keywords: Lamin, Long non-coding RNA, MicroRNA, Myelin

\section{Introduction}

Compact concentric wraps of myelin, a unique characteristic of vertebrates, can speed up propagation of electrical activities along axons in the nervous system. Myelin sheath consists of membranous outgrowth from specified glia such as oligodendrocytes in the central nervous system (CNS) and Schwann cells in the peripheral nervous system. In adults, oligodendrocytes are generated by proliferation or migration of oligodendrocyte progenitors cells $(\mathrm{OPC})$ throughout the CNS, followed by differentiation into post-mitotic pre-myelinating oligodendrocytes and myelination of adjacent axons when

\footnotetext{
* Correspondence: ying-hui.fu@ucsf.edu

'Department of Neurology, University of California, 1550 Fourth street, UCSF-Mission Bay, Rock Hall 548, San Francisco, CA 94158, USA Full list of author information is available at the end of the article
}

appropriate environmental cues are present [1-6]. Molecular mechanisms underlying oligodendrocyte differentiation and CNS myelination include intrinsic cues such as transcriptional factors, microRNAs (miRNAs), and chromatin remodeling, and extrinsic signaling such as extracellular ligands and neuronal activities [1]. A number of transcription factors have been identified that promote oligodendrocyte specification $[7,8]$, differentiation, myelination [7-13], or prevent OPC from differentiating [14-17]. Failure to integrate these molecular mechanisms may lead to myelin malformation or premature breakdown of myelin similar to that observed in human diseases such as hereditary leukodystrophies or multiple sclerosis. In this review, we address adult onset autosomal dominant leukodystrophy (ADLD), recently shown to be caused by increased expression of lamin B1 resulting from duplication 
of the gene encoding lamin B1, LMNB1 [18-24], or possibly its dysregulation [25]. Importantly, the adverse effect of $L M N B 1$ overexpression in oligodendrocytes can be abrogated by $m i R-23$, suggesting that it may be a negative regulator of lamin B1 [26]. Therefore, we will discuss the clinical presentation of ADLD, and how lamin B1 affects myelination (both when in excess and in its absence). Moreover, we discuss the emerging role of non-coding RNAs (ncRNAs) in modulating gene networks, specifically investigating $m i R-23$ as a potential target for the treatment of ADLD and other demyelinating disorders.

\section{Clinical presentation of adult-onset autosomal dominant leukodystrophy}

ADLD was originally reported for a large American-Irish family carrying a progressive and fatal neurological white matter disorder [27]. Additional ADLD families were subsequently found in other ethnic groups [19,28-33]. Typical ADLD symptoms begin between the forth and sixth decades of life with early presentation of autonomic symptoms, including bowel/bladder dysfunction, impotence in males, and orthostatic hypotension [34-36]. Recent evidence of delayed onset of autonomic dysfunction in a Serbian family with $L M N B 1$-dupication presents a variant of the ADLD symptoms [31]. Clinically, it is a progressive degenerative neurological disorder characterized by pyramidal, cerebellar, and autonomic abnormalities [27,29,30,37]. Autonomic symptoms are followed by cerebellar impairment (ataxia, dysmetria, nystagmus, and action tremors) and pyramidal abnormalities (spasticity and weakness of both upper and lower extremities). Cardiovascular and pharmacological assessments indicate a selective sympathetic failure with spared cardiovagal response [36,38]. Mild cognitive, visual, and auditory abnormalities are also found in some cases. Selective loss of noradrenergic fibers with preserved cholinergic fibers in skin biopsy of a patient with ADLD [36] indicates autonomic neuropathy. However, peripheral nerve, sympathetic ganglia, vagus nerve, and adrenal medulla did not exhibit obvious abnormality at autopsy [38]. The MRI scans display diffused, confluent and symmetric white matter degeneration starting in the frontoparietal region, extending towards the brainstem and cerebellar white matter [30,35,39]. Periventricular white matter appears less involved than the adjacent white matter [30]. The diameter of the medulla oblongata is reduced in the coronal plane and the corpus callosum is also atrophic. White matter changes are most significant in the brain though spinal cord involvement has been reported in some cases [40]. Neuropathological findings reveal white matter abnormalities in the frontoparietal and cerebellar white matter but spare the cortex and subcortical $U$ fiber in symptomatic ADLD patients [30,35]. Light microscopy showed vacuolated white matter with no significant loss of oligodendroglia, which has no clear sign of inflammatory changes and reactive astrocytosis [30,35]. In addition, sparse astrocytes with intense immunoreactivities against insulin-like growth factor-1 and vimentin are accompanied by beaded/foreshortened morphology or thickening processes. Reduced numbers of Purkinje cells and slightly increased numbers of Bergmann cells in cerebellum are also found [30]. Lacking significant inflammatory infiltrates, activated microglia, or macrophages, this disorder does not appear to result from the direct autoimmune attack on myelin proteins that is present in multiple sclerosis. Overall, preservation of oligodendroglia in the presence of demyelination and the lack of or moderate astrogliosis under light microscopy are the unique features of ADLD [30,35]. Genetic evidence demonstrates that ADLD is caused by duplication of $L M N B 1$ in the majority of ADLD patients [18-24], and recent study from twenty families revealed a minimal $72 \mathrm{~kb}$ of LMNB1 duplication required for the disease [23]. However, how this mutation leads to these described cellular phenotypes is not completely clear. Therefore, in the next section we survey current research on lamin B1 and how over- or under-expression of this protein can dysregulate myelination.

\section{Lamin B1 is integral to the nuclear lamina and regulates gene expression}

Lamins are structural components of the nuclear lamina, which is a filamentous meshwork of proteins underlying the inner nuclear membrane. Nuclear lamina has been found to play dynamic roles in the organization and regulation of chromatin, transcription, DNA replication, DNA repair, and various epigenetic phenomena such as euchromatin and heterochromatin transitions [41]. RNA interference-mediated knocking down of the only lamin, Ce-lamin, in C. elegans leads to embryonic lethality due to defects in cell cycle progression, chromosome segregation, chromatin organization and correct spacing of nuclear pore complexes [42]. Similarly, depletion of the B-type lamin, lamin Dm0, in Drosophila cultured cells and embryos by RNA interference results in morphological alterations of nuclei, nuclear fragility and the arrest of embryonic development [43]. Mammalian cells have two major types of lamins, A-type and B-type, and mutations in genes encoding the nuclear lamins can cause a wide range of human diseases, collectively called laminopathies (for review, see [44-47]). B-type lamins include lamin B1 encoded by $L M N B 1$ (mouse $L m n b 1$ ) and lamin B2 encoded by LMNB2 (mouse Lmnb2). Lamins anchor chromatin to the nuclear lamina and act as a scaffold for chromatin remodeling, and are thus critical for determining spatial organization of chromosomes in the nucleus [48]. Furthermore, genomic regions tethered to the nuclear periphery were shown to be associated with reduced transcription of genes in the region, suggesting that lamins 
may play an active role in regulating transcription as well $[49,50]$. Cells isolated from human with laminopathies or murine models with lamin deficiency all displayed abnormal nuclear structures [51-53]. Numerous diseases are associated with $L M N A$ mutations, with symptoms ranging from myopathy, lipodystrophy, accelerated aging disorders, peripheral neuropathy, to bone disorders $[46,54]$. Recent studies in murine models of Lmna mutations suggest that mutations in the A-type lamin confer phenotypes by gain-of-function toxicity for some models and loss-offunction for others [46]. In contrast, myelin disease is the only reported phenotype associated with $L M N B 1$ duplications [18] while acquired partial lipodystrophy is associated with mutations in LMNB2 [55]. Lamin B1 has been reported to play a role in cell proliferation and senescence in culture [56-58], and both silencing and overexpressing lamin B1 have been linked to senescence [56,57,59]. However, the B-type lamins do not affect the development of skin keratinocytes and hepatocytes [60,61], which appear morphologically normal in histological analyses. Given that lamin B1 binds to genes whose expression are not essential for proliferation and survival or in vitro lineage specification in embryonic stem cells [62], we propose that lamin A and lamin B1 control different sets of gene expression through direct chromatin-binding, and that Btype lamins may specifically affect neural development, whereas A-type lamins may preferentially affect other cell types. During differentiation, differences in temporal and spatial expression of A-type and B-type lamins will result in different chromatin patterns, thus conferring unique transcriptome signatures of cell lineage.

\section{Lamin B1 is necessary for proper cellular development}

Consistent with its proposed role in regulating specific gene expression, lamina-associated domains of lamin B1 are connected to genome regions with low expression levels, exhibiting lower levels of active chromatin, and enriched with silenced chromatin markers that indicate repressive chromatin organization [62-65]. The high-resolution genome-nuclear lamina interaction maps of lamin B1 in pluripotent embryonic stem cells, multipotent precursor cells, and terminal differentiated cells revealed a dynamic interaction of nuclear lamina and genes in the genome according to cell type, differentiation steps, and gene expression levels that correlate with subsequent repression or activation [66]. These unique characteristics of lamin B1 suggest its importance in cellular development that requires temporal and spatial regulation of gene networks.

Supporting this hypothesis, Drosophila testis' nuclear lamin-B regulates cyst stem cell differentiation and organization of the niche through nuclear epidermal growth factor receptor signaling [67]. Furthermore, deficiencies of lamin B1 and/or lamin B2 in mice lead to perinatal lethality, especially due to poor lung development $[51,62,68,69]$. Knockout of Lmnb1/2 or Lmnb1 alone also results in microcephaly. Despite developmental impairment, lamin B2 deficiency has comparatively better-developed lung, brain, and diaphragm, suggesting a possible functional redundancy between the B-type lamins $[62,68]$. In recent years, lamin B1 and lamin B2 have been demonstrated to play a critical role in neuronal migration in mouse cerebral cortex and cerebellum $[52,62,68]$. Impairment of neuronal migration in cortex was attributed to improper connection between cytoskeleton and the nucleus [62], which is consistent with increased nuclear spinning (an indication for impairment in anchoring the nucleus to cytoskeleton) in fibroblasts cultured from $L m n b 1^{\Delta / \Delta}$ mice [70]. Similarly, spindle orientation defects have been identified in cerebral cortex in Lmnb1 knockout mice that lead to defects in division of neural progenitor cells [71]. In addition, accelerated cell cycle exit and enhanced apoptosis in cerebral cortex of Lmnb1 knockout mice suggest that lamin B1 may also modulate proliferation potential and differentiation of neural progenitor cells and neurons in the embryonic brain [62].

The mammalian lamin B1 is post-translationally modified by farnesylation, endoproteolysis, and carboxymethylation at a carboxyl-terminal CaaX motif [72], and its specific interacting portions appear to be important for its function. For example, gene trap insertion in mouse resulting in an allele encoding lamin B1 lacking the $\mathrm{C}$ terminus causes perinatal lethality due to lung and bone abnormalities [51]. Furthermore, impaired farnesylation of lamin B1 leads to loss of chromatin anchor to the nuclear lamina, and causes migratory defects of neurons in brains and perinatal lethality [73]. Together, these results suggest that developmental processes are highly sensitive to both the expression level and post-translational modifications of lamin B1. Interestingly, lamin B1 itself in the brain is developmentally regulated, with levels peaking at birth or postnatal day 1 , followed by a gradual decrease from postnatal day 1 to 10 months of age [26] whereas levels of many myelin proteins in the murine brain gradually increase with age in a pattern that is complementary to that of lamin B1. These results imply a possible role for lamin $\mathrm{B} 1$ in the regulation of oligodendrocyte development or myelin proteins expression.

\section{Lamin B1 overexpression leads to demyelination}

Overexpression of the B-type lamins was previously shown to promote nuclear membrane growth and intranuclear membrane formation in amphibian oocytes, epithelium, and mammalian kidney cells in a CaaX motif-dependent manner [74,75]. In agreement with these findings, ectopic overexpression of lamin B1 in neural and glial cell lines increase surface area of nuclear membrane and intranuclear aggregates [26]. Increased expression of lamin B1 also 
results in perturbations of inner nuclear membrane proteins, chromatin organization, and nuclear pore transport. It is possible that formation of abnormal intranuclear membranes caused by excessive lamin B1 production leads to the altered subcellular localization of nuclear envelope proteins and perturbed nuclear transport, especially in oligodendrocytes. Supporting this hypothesis, widespread overexpression of lamin B1 in mouse brain using bacterial artificial chromosome (BAC) transgenic engineering recapitulates many of the clinical features present in ADLD, including aberrant myelin formation, axonal degeneration and demyelination [76]. $L M N B 1^{\mathrm{BAC}}$ mice exhibit seizure, cognitive impairment, and motor deficits, which progressively worsen with age. Remarkably, lineage-specific overexpression of lamin B1 in mouse oligodendroglia is sufficient for reproducing the histopathological, molecular and behavioral abnormalities in ADLD. Although decreased abundance of myelin protein, proteolipid protein (PLP), attributed to loss of occupancy of a transcription activator, Yin Yang 1 (YY1) on its promoter, contributes at least in part to the myelin phenotype in ADLD, the possibility that an independent degenerative process of myelin also contributes to the phenotype has not been excluded. Nevertheless, these results suggest that genes required for myelin proteins and oligodendrocyte maturation are sensitive to changes in lamin $\mathrm{B} 1$ abundance. Indeed, the effects of lamin B1 overexpression on gene transcription were demonstrated by the repression of myelin-specific genes [76] and the activation of GFAP transcription in oligodendroglial cell lines [26]. Lamin B1 is associated with an oxidative stress pathway transcriptional factor, octamer transcription factor 1 (Oct-1), in normal mouse fibroblasts [77]. Fibroblast cells lacking full-length lamin B1 are vulnerable to oxidative stress similar to what is found in Oct-1 knockout cells. In fibroblasts cultured from ADLD patients, Oct-1 was increased at the nuclear periphery with reduced nucleoplasmic localization under oxidative stress conditions [78]. However, whether Oct-1 participates in the regulation of myelin gene expression and other developmental defects in the CNS require further investigation. Supporting in vivo findings, in a primary culture system, transient overexpression of lamin B1 in oligodendrocytes by lentiviral transduction causes defects in myelin protein expression and differentiation accompanied by mild nuclear envelope growth/distortion [26]. Overall, these results indicate that overexpression of lamin B1 could disturb the unique gene expression patterns in individual CNS cell types and that these phenotypes would only appear in certain cell types that are vulnerable to transcriptional perturbance during differentiation. These studies identify a mechanism by which excessive lamin B1 expression can cause oligodendrocyte cell-autonomous neuropathology in ADLD, and implicate lamin B1 as an important factor for myelin formation and maintenance.
Therefore, identifying upstream regulators of lamin B1 may provide a means of treating de/dysmyelinating disorders such as ADLD.

\section{MiRNA-23 regulates myelination through multiple targets including LMNB1}

Recently, miRNAs are implicated to regulate a large number of developmental processes and diseases through finetuning biological networks [79-84]. Expression levels of miRNAs in oligodendroglia vary according to their state of differentiation, indicating a possible role for miRNAs in regulating oligodendrocyte development [85-88]. Notably, specific miRNAs regulate various important factors in progenitor stages and during OPC differentiation [87-89]. In addition, ablation of miRNA cluster (miR-17-92) perturbs oligodendrocyte proliferation through targeting phosphatase and tensin homolog on chromosome 10 (PTEN) [86]. Moreover, disruption of miRNA biogenesis by Dicer ablation in oligodendroglia at post-developmental stages results in a neurodegenerative phenotype including demyelination, inflammation, and axon loss [90], suggesting that miRNAs are also important for myelin maintenance at later developmental stages. Therefore, expression of miRNAs at different stages is thought to promote differentiation by antagonizing suppressive factors in progenitors and/or to keep oligodendrocytes at a mature stage for myelin maintenance.

As excessive lamin B1 expression appears to be the sole cause of ADLD, understanding its regulation may provide insight into potential treatment methods. To determine whether lamin B1 can be regulated by miRNAs, several miRNAs predicted to target $L M N B 1$ were screened (TargetScan: http://www.targetscan.org/vert_42/). miRNA23 ( $m i R-23)$ is among the most abundant miRNAs in oligodendrocytes $[85,86]$ and is able to counteract the expression of Lmnb1 [26,57]. In the presence of excess $m i R-23$ in cell culture, a greater proportion of cells express mature markers of oligodendrocytes that are accompanied by multipolar morphological appearance and increased levels of mature myelin proteins, indicating that miR-23 can enhance differentiation. In contrast, excessive lamin B1 leads to defective differentiation of oligodendrocytes. Importantly, the adverse effect of lamin B1 on oligodendrocyte cells can be abrogated by $m i R-23$ as a negative regulator of lamin B1 [26]. Consistent with these observations, the developmental expression pattern of miR-23 in vivo is reciprocal to that of the lamin B1 [26,91].

The in vivo effects of miR-23 on oligodendrocyte differentiation and myelin formation in the CNS were validated by transgenic mice overexpressing mmu-miR-23a driven by an oligodendrocyte specific promoter [2', 3'-cyclic ucleotide 3'-phophodiesterase (Cnp)] [91]. These mice exhibit increased myelin thickness, providing in vivo evidence that $m i R-23 a$ enhances myelin synthesis [91]. 
To explore possible $m i R-23 a$ targets that are important for CNS myelination, RNA-Seq approach was applied to examine oligodendrocytes derived from both $m i R-23 a$ transgenic mice and control littermates. PTEN was identified as a potential target and further characterization confirmed that the PTEN/PI3K/Akt/mTOR pathway is modulated by miR-23a (Figure 1). Interestingly, a long non-coding RNA (lncRNA) neighboring PTEN, 2700046G09Rik, was identified in the same study as another $m i R-23 a$ target and modulates PTEN itself in a miR-23a dependent manner. These data implicate a novel role for $m i R-23 a$ in the coordination of proteins and non-coding RNAs for generating and maintaining healthy myelin [91]. IncRNAs have recently been shown to function as transcriptional and post-transcriptional regulators of gene expression, such as through modulation of chromatin modifications, or transcriptional interference by antisense transcription [83,92]. miR-23a upregulates 2700046G09Rik transcription, and $2700046 G 09 R i k$ in turn lengthens the half-life of $m i R-23 a$, thus potentiating its repressive effects. 2700046G09Rik can also target its neighboring gene PTEN and lead to a reduction in PTEN levels. Therefore, repressive effects on PTEN can either occur with $m i R-23 a$ alone or in coordination with 2700046G09Rik. In addition, 2700046G09Rik may aid in the cellular re-compartmentation of $m i R-23 a$ into P-bodies, which could also contribute to the regulation of PTEN levels, suggesting that interplay of $m i R-23 a$ and 2700046G09Rik infers additional molecular regulation of mRNA decay [91].

2700046G09Rik is expressed higher in oligodendrocytes under differentiation conditions than OPCs or astrocytes. The presence of 2700046 G09Rik in oligodendroglia potentiates and signals the activation of the miR-23a-PTEN/ Akt-mTOR cascades in the correct developmental stage, thus regulating the expression of myelin genes in oligodendrocytes. In addition, two important transcription factors (YY1 and Nkx2.2) for oligodendroglia [10,11,93] act on the promoter of $2700046 \mathrm{G} 09 \mathrm{Rik}$, leading to its transactivation during oligodendrocyte development. These findings are consistent with the emerging notion that dynamic changes of lncRNAs are important for glia differentiation [94]. Intriguingly, YY1 occupancy at PLP promoter is reduced in the $L M N B 1^{\mathrm{BAC}}$ mice as described earlier [76]. All in all, these findings further highlight the complexity of oligodendrocyte/myelin regulatory pathways, as demonstrated by the coordination of transcriptional (transcription factors) and post-transcriptional (miRNA and lncRNA) mechanisms.

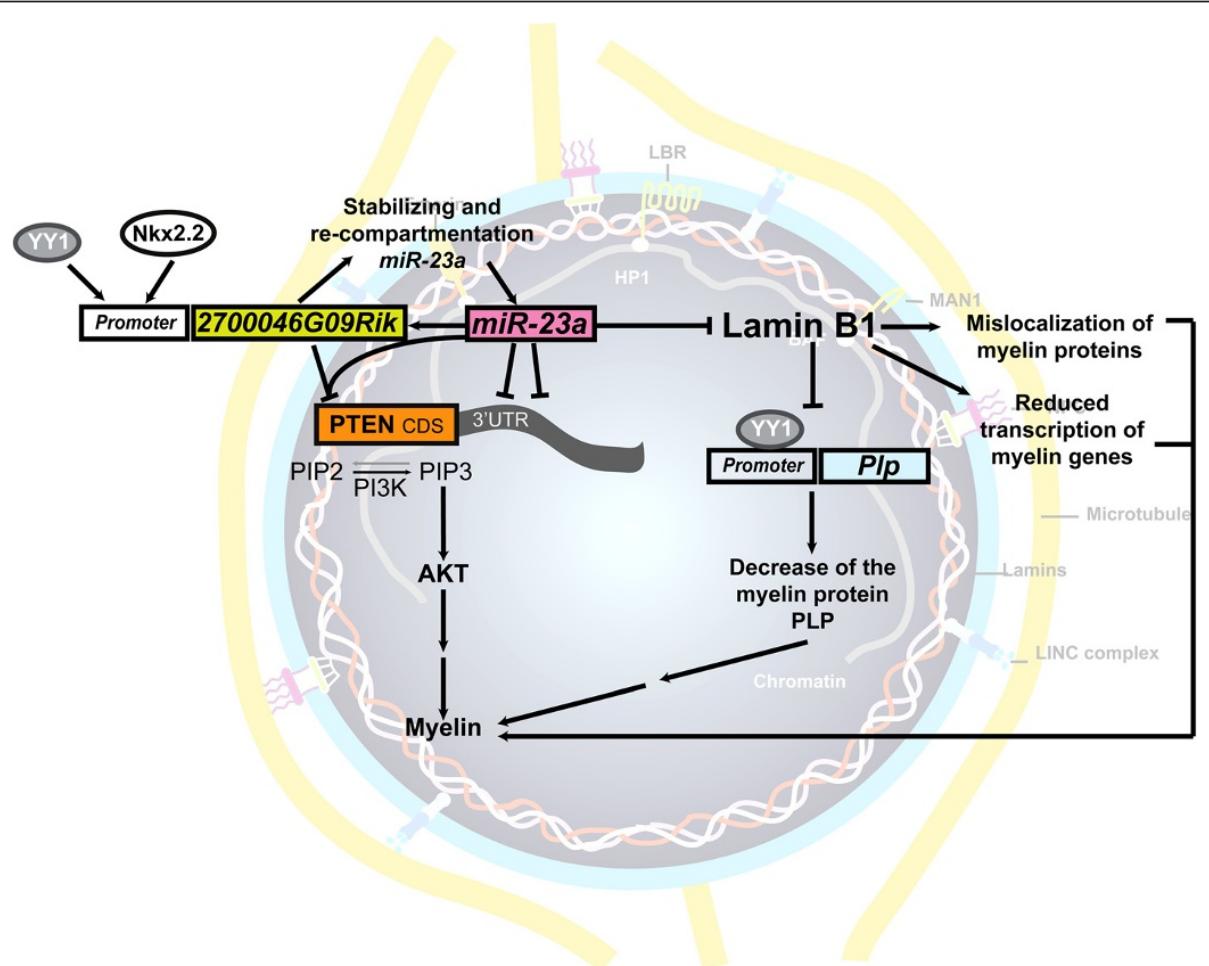

Figure 1 Model for the mechanism of miR-23a in regulating myelination. MiR-23a enhances 2700046G09Rik and represses PTEN and lamin B1 in oligodendroglia. Lamin B1 overexpression reduces the occupancy of YY1 on P/p promoter, decreases transcription of myelin genes, and causes mislocalization of myelin proteins. 2700046G09Rik interacts with and stabilizes miR-23a. In addition, 2700046G09Rik re-compartments and alters miR-23a sub-cellular localization, which further enhances repressive effects of miR-23a on PTEN. Less PTEN in antagonizing PI3K activity leads to AKT activation which then results in myelination. miR-23a represses lamin B1 leading to increased myelination. 


\section{Conclusion}

Taken together, in vitro and in vivo investigations of ADLD have established the importance of nuclear lamins, miRNA, and ncRNA in oligodendroglial development, and provide potential therapeutic approaches for myelin diseases. For example, $m i R-23 a$ may ameliorate reduced levels of oligodendrocyte- and myelin-specific proteins in ADLD. In addition, miR-23 can also enhance oligodendrocyte development through other lamin B1 independent pathways such as PTEN/Akt/mTOR. Genetic interaction studies using mouse models in the future will further reveal lamin B1 dependent and independent effects of $m i R-23 a$, and thus determine the possibility of developing non-coding RNAs as potential therapeutic intervention as well. Although ADLD is a rare disease, it has provided us with new knowledge on nuclear events underlying myelin maintenance and events leading to premature myelin breakdown [76]. Understanding the function of lamins in the context of lamin-binding-chromatin organization will also unveil novel mechanisms that mediate myelin diseases, aging process, and other biological functions.

To date, the duplication of $L M N B 1$ is the only disease that links nuclear structure to myelin formation in the CNS [18]. Interestingly, duplication of PLP1 is one of the most common causes of demyelination in PelizaeusMerzbacher disease $[95,96]$. Overexpression of the common myelin protein, PLP, causes endoplasmic reticulum stress, leading to oligodendrocyte demise [97]. It will be intriguing to investigate threshold effect of gene transcription and translation on myelin formation and other biological mechanisms where gene and protein expression homeostasis are critical. Likewise, identification of upstream enhancer/repressor elements that can modulate miRNA expression and additional downstream effectors of lamin B1 and $m i R-23$ may provide novel insights into the mechanisms of oligodendrocyte development, myelin formation, and maintenance. The $L M N B 1^{\mathrm{BAC}}$ mouse model overexpressing lamin B1, mimicking human ADLD, will be a critical resource for further investigations in vivo, because while increased lamin B1 expression in neurons or glia causes lethality in Drosophila [18], the striking similarities between human and murine oligodendrocytes may hasten investigations toward clinical development. Growing understanding of human-relevant pathways critical for myelin regulation will provide novel screening targets for the treatment of ADLD and other myelin-based disorders.

\section{Competing interests}

The authors declare that they have no competing interests.

\section{Authors' contributions}

STL and MYH carried out literature search and drafted the manuscript. LJP and YHF, the supervisors of the research group, provided the guidance and instructions and critically revised the manuscript. All authors read and approved the final manuscript.

\section{Acknowledgements}

We apologize to all colleagues whose important work could not be cited owing to space limitations. The authors thank S.Y.C. Chong for helpful discussion and editing of the manuscript. This work was supported by the NIH NS062733 to Y.-H.F., and Sandler Neurogenetics Fund to Y.-H.F and L.J. P. L.J.P. is an investigator of the Howard Hughes Medical Institute.

\section{Author details}

${ }^{1}$ Department of Neurology, University of California, 1550 Fourth street, UCSF-Mission Bay, Rock Hall 548, San Francisco, CA 94158, USA. ${ }^{2}$ Howard Hughes Medical Institute, University of California, San Francisco, CA 94158, USA.

Received: 11 December 2013 Accepted: 1 February 2014

Published: 5 February 2014

\section{References}

1. Emery B: Regulation of oligodendrocyte differentiation and myelination. Science 2010, 330:779-782.

2. Barres BA: The mystery and magic of glia: a perspective on their roles in health and disease. Neuron 2008, 60:430-440.

3. Aguirre A, Dupree $\mathrm{JL}$, Mangin JM, Gallo V: A functional role for EGFR signaling in myelination and remyelination. Nat Neurosci 2007, 10:990-1002.

4. Rivers LE, Young KM, Rizzi M, Jamen F, Psachoulia K, Wade A, Kessaris N, Richardson WD: PDGFRA/NG2 glia generate myelinating oligodendrocytes and piriform projection neurons in adult mice. Nat Neurosci 2008, 11:1392-1401.

5. Noble M: Precursor cell transitions in oligodendrocyte development. J Cell Biol 2000, 148:839-842.

6. Kriegstein A, Alvarez-Buylla A: The glial nature of embryonic and adult neural stem cells. Annu Rev Neurosci 2009, 32:149-184.

7. Zhou Q, Choi G, Anderson DJ: The bHLH transcription factor Olig2 promotes oligodendrocyte differentiation in collaboration with Nkx2.2. Neuron 2001, 31:791-807.

8. Lu QR, Sun T, Zhu Z, Ma N, Garcia M, Stiles CD, Rowitch DH: Common developmental requirement for Olig function indicates a motor neuron/oligodendrocyte connection. Cell 2002, 109:75-86.

9. Parras CM, Hunt C, Sugimori M, Nakafuku M, Rowitch D, Guillemot F: The proneural gene Mash1 specifies an early population of telencephalic oligodendrocytes. J Neurosci 2007, 27:4233-4242.

10. Qi Y, Cai J, Wu Y, Wu R, Lee J, Fu H, Rao M, Sussel L, Rubenstein J, Qiu M: Control of oligodendrocyte differentiation by the Nkx2.2 homeodomain transcription factor. Development 2001, 128:2723-2733.

11. He Y, Dupree J, Wang J, Sandoval J, Li J, Liu H, Shi Y, Nave KA, CasacciaBonnefil P: The transcription factor Yin Yang 1 is essential for oligodendrocyte progenitor differentiation. Neuron 2007, 55:217-230.

12. Wegner $\mathrm{M}$ : Expression of transcription factors during oligodendroglial development. Microsc Res Tech 2001, 52:746-752.

13. Clevers $\mathrm{H}$ : Wnt/beta-catenin signaling in development and disease. Cell 2006, 127:469-480.

14. Wang S, Sdrulla A, Johnson JE, Yokota Y, Barres BA: A role for the helixloop-helix protein Id 2 in the control of oligodendrocyte development. Neuron 2001, 29:603-614.

15. Kondo T, Raff M: The Id4 HLH protein and the timing of oligodendrocyte differentiation. EMBO J 2000, 19:1998-2007.

16. Liu A, Li J, Marin-Husstege M, Kageyama R, Fan Y, Gelinas C, CasacciaBonnefil P: A molecular insight of Hes5-dependent inhibition of myelin gene expression: old partners and new players. EMBO J 2006, 25:4833-4842.

17. Stolt CC, Schlierf A, Lommes P, Hillgartner S, Werner T, Kosian T, Sock E, Kessaris N, Richardson WD, Lefebvre $V$, Wegner M: SoxD proteins influence multiple stages of oligodendrocyte development and modulate SoxE protein function. Dev Cell 2006, 11:697-709.

18. Padiath QS, Saigoh K, Schiffmann R, Asahara H, Yamada T, Koeppen A, Hogan K, Ptacek LJ, Fu YH: Lamin B1 duplications cause autosomal dominant leukodystrophy. Nat Genet 2006, 38:1114-1123.

19. Meijer IA, Simoes-Lopes AA, Laurent S, Katz T, St-Onge J, Verlaan DJ, Dupre N, Thibault M, Mathurin J, Bouchard JP, Rouleau GA: A novel duplication confirms the involvement of 5q23.2 in autosomal dominant leukodystrophy. Arch Neurol 2008, 65:1496-1501. 
20. Schuster J, Sundblom J, Thuresson AC, Hassin-Baer S, Klopstock T, Dichgans M, Cohen OS, Raininko R, Melberg A, Dahl N: Genomic duplications mediate overexpression of lamin B1 in adult-onset autosomal dominant leukodystrophy (ADLD) with autonomic symptoms. Neurogenetics 2011, 12:65-72.

21. Molloy A, Cotter O, van Spaendonk R, Sistermans E, Sweeney B: A patient with a rare leukodystrophy related to lamin B1 duplication. Ir Med J 2012, 105:186-187.

22. Dos Santos MM, Grond-Ginsbach C, Aksay SS, Chen B, Tchatchou S, Wolf NI, van der Knaap MS, Grau AJ: Adult-onset autosomal dominant leukodystrophy due to LMNB1 gene duplication. J Neurol 2012, 259:579-581.

23. Giorgio E, Rolyan H, Kropp L, Chakka AB, Yatsenko S, Gregorio ED, Lacerenza D, Vaula G, Talarico F, Mandich P, et al: Analysis of LMNB1 duplications in autosomal dominant leukodystrophy provides insights into duplication mechanisms and allele-specific expression. Hum Mutat 2013, 34:1160-1171.

24. Brussino A, Vaula G, Cagnoli C, Mauro A, Pradotto L, Daniele D, Di Gregorio E, Barberis M, Arduino C, Squadrone S, et al: A novel family with Lamin B1 duplication associated with adult-onset leucoencephalopathy. J Neurol Neurosurg Psychiatry 2009, 80:237-240.

25. Brussino A, Vaula G, Cagnoli C, Panza E, Seri M, Di Gregorio E, Scappaticci S, Camanini S, Daniele D, Bradac GB, et al: A family with autosomal dominant leukodystrophy linked to 5q23.2-q23.3 without lamin B1 mutations. Eur J Neurol 2010, 17:541-549.

26. Lin ST, Fu YH: miR-23 regulation of lamin B1 is crucial for oligodendrocyte development and myelination. Dis Model Mech 2009, 2:178-188.

27. Eldridge R, Anayiotos CP, Schlesinger S, Cowen D, Bever C, Patronas N, McFarland $\mathrm{H}$ : Hereditary adult-onset leukodystrophy simulating chronic progressive multiple sclerosis. N Engl J Med 1984, 311:948-953.

28. Asahara H, Yoshimura T, Sada S, Furuya H, Kobayashi T: [A Japanese family with probably autosomal dominant adult-onset leukodystrophy]. Rinsho Shinkeigaku = Clinical Neurology 1996, 36:968-972.

29. Marklund L, Melin M, Melberg A, Giedraitis V, Dahl N: Adult-onset autosomal dominant leukodystrophy with autonomic symptoms restricted to $1.5 \mathrm{Mbp}$ on chromosome $5 \mathrm{q} 23$. Am J Med Genet B Neuropsychiatr Genet 2006, 141B:608-614.

30. Melberg A, Hallberg L, Kalimo H, Raininko R: MR characteristics and neuropathology in adult-onset autosomal dominant leukodystrophy with autonomic symptoms. AJNR Am J Neuroradiol 2006, 27:904-911.

31. Potic A, Pavlovic AM, Uziel G, Kozic D, Ostojic J, Rovelli A, Sternic N, Bjelan M, Sarto E, Di Bella D, Taroni F: Adult-onset autosomal dominant leukodystrophy without early autonomic dysfunctions linked to lamin B1 duplication: a phenotypic variant. J Neurol 2013, 260:2124-2129.

32. Quattrocolo G, Leombruni S, Vaula G, Bergui M, Riva A, Bradac GB, Bergamini L: Autosomal dominant late-onset leukoencephalopathy: clinical report of a new Italian family. Eur Neurol 1997, 37:53-61.

33. Abe K, Ikeda M, Watase K, Tanabe H, Fujimura H, Yorifuji S, Ueno S, Mezaki T, Mori T: A kindred of hereditary adult-onset leukodystrophy with sparing of the optic radiations. Neuroradiology 1993, 35:281-283.

34. Schwankhaus JD, Patronas N, Dorwart R, Eldridge R, Schlesinger S, McFarland $\mathrm{H}$ : Computed tomography and magnetic resonance imaging in adult-onset leukodystrophy. Arch Neurol 1988, 45:1004-1008.

35. Coffeen CM, McKenna CE, Koeppen AH, Plaster NM, Maragakis N, Mihalopoulos J, Schwankhaus JD, Flanigan KM, Gregg RG, Ptacek LJ, Fu YH: Genetic localization of an autosomal dominant leukodystrophy mimicking chronic progressive multiple sclerosis to chromosome $5 q 31$. Hum Mol Genet 2000, 9:787-793.

36. Guaraldi P, Donadio V, Capellari S, Contin M, Casadio MC, Montagna P, Liguori R, Cortelli P: Isolated noradrenergic failure in adult-onset autosomal dominant leukodystrophy. Auton Neurosci 2011, 159:123-126.

37. Cortelli $P$, Terlizzi R, Capellari S, Benarroch E: Nuclear lamins: functions and clinical implications. Neurology 2012, 79:1726-1731.

38. Brown RT, Polinsky RJ, Schwankhaus J, Eldridge R, McFarland H, Schlesinger S, Dailey WA: Adrenergic dysfunction in hereditary adult-onset leukodystrophy. Neurology 1987, 37:1421-1424.

39. Bergui M, Bradac GB, Leombruni S, Vaula G, Quattrocolo G: MRI and CT in an autosomal-dominant, adult-onset leukodystrophy. Neuroradiology 1997, 39:423-426.

40. Sundblom J, Melberg A, Kalimo H, Smits A, Raininko R: MR imaging characteristics and neuropathology of the spinal cord in adult-onset autosomal dominant leukodystrophy with autonomic symptoms. AJNR Am J Neuroradiol 2009, 30:328-335.
41. Dechat T, Gesson K, Foisner R: Lamina-independent lamins in the nuclear interior serve important functions. Cold Spring Harb Symp Quant Biol 2010, 75:533-543.

42. Liu J, Rolef Ben-Shahar T, Riemer D, Treinin M, Spann P, Weber K, Fire A, Gruenbaum Y: Essential roles for Caenorhabditis elegans lamin gene in nuclear organization, cell cycle progression, and spatial organization of nuclear pore complexes. Mol Biol Cell 2000, 11:3937-3947.

43. Wagner N, Weber D, Seitz S, Krohne G: The lamin B receptor of Drosophila melanogaster. J Cell Sci 2004, 117:2015-2028.

44. Worman HJ, Ostlund C, Wang Y: Diseases of the nuclear envelope. Cold Spring Harb Perspect Biol 2010, 2:a000760.

45. Worman HJ, Bonne G: "Laminopathies": a wide spectrum of human diseases. Exp Cell Res 2007, 313:2121-2133.

46. Schreiber $\mathrm{KH}$, Kennedy BK: When lamins go bad: nuclear structure and disease. Cell 2013, 152:1365-1375.

47. Burke B, Stewart CL: The nuclear lamins: flexibility in function. Nat Rev Mol Cell Biol 2013, 14:13-24.

48. Vlcek S, Foisner R: Lamins and lamin-associated proteins in aging and disease. Curr Opin Cell Biol 2007, 19:298-304.

49. Finlan LE, Sproul D, Thomson I, Boyle S, Kerr E, Perry P, Ylstra B, Chubb JR, Bickmore WA: Recruitment to the nuclear periphery can alter expression of genes in human cells. PLoS Genet 2008, 4:e1000039.

50. Reddy $\mathrm{KL}$, Zullo JM, Bertolino $\mathrm{E}$, Singh $\mathrm{H}$ : Transcriptional repression mediated by repositioning of genes to the nuclear lamina. Nature 2008, 452:243-247.

51. Vergnes L, Peterfy M, Bergo MO, Young SG, Reue K: Lamin B1 is required for mouse development and nuclear integrity. Proc Natl Acad Sci USA 2004, 101:10428-10433.

52. Coffinier $C$, Jung HJ, Nobumori $C$, Chang S, Tu Y, Barnes RH 2nd, Yoshinaga $Y$, de Jong PJ, Vergnes L, Reue $K$, et al: Deficiencies in lamin B1 and lamin B2 cause neurodevelopmental defects and distinct nuclear shape abnormalities in neurons. Molec Bio/ Cell 2011, 22:4683-4693.

53. Goldman RD, Shumaker DK, Erdos MR, Eriksson M, Goldman AE, Gordon LB, Gruenbaum Y, Khuon S, Mendez M, Varga R, Collins FS: Accumulation of mutant lamin $A$ causes progressive changes in nuclear architecture in Hutchinson-Gilford progeria syndrome. Proc Natl Acad Sci USA 2004, 101:8963-8968.

54. Dauer WT, Worman HJ: The nuclear envelope as a signaling node in development and disease. Dev Cell 2009, 17:626-638.

55. Hegele RA, Cao H, Liu DM, Costain GA, Charlton-Menys V, Rodger NW Durrington PN: Sequencing of the reannotated LMNB2 gene reveals novel mutations in patients with acquired partial lipodystrophy. Am J Hum Genet 2006, 79:383-389.

56. Shimi T, Butin-Israeli V, Adam SA, Hamanaka RB, Goldman AE, Lucas CA, Shumaker DK, Kosak ST, Chandel NS, Goldman RD: The role of nuclear lamin B1 in cell proliferation and senescence. Genes \& Dev 2011 25:2579-2593.

57. Dreesen O, Chojnowski A, Ong PF, Zhao TY, Common JE, Lunny D, Lane EB, Lee SJ, Vardy LA, Stewart CL, Colman A: Lamin B1 fluctuations have differential effects on cellular proliferation and senescence. J Cell Biol 2013, 200:605-617

58. Freund A, Laberge RM, Demaria M, Campisi J: Lamin B1 loss is a senescence-associated biomarker. Mol Biol Cell 2012, 23:2066-2075.

59. Barascu A, Le Chalony C, Pennarun G, Genet D, Imam N, Lopez B, Bertrand P: Oxidative stress induces an ATM-independent senescence pathway through p38 MAPK-mediated lamin B1 accumulation. EMBO J 2012, 31:1080-1094.

60. Yang SH, Chang SY, Yin L, Tu Y, Hu Y, Yoshinaga Y, de Jong PJ, Fong LG, Young SG: An absence of both lamin B1 and lamin B2 in keratinocytes has no effect on cell proliferation or the development of skin and hair. Hum Mol Genet 2011, 20:3537-3544.

61. Yang SH, Jung HJ, Coffinier C, Fong LG, Young SG: Are B-type lamins essential in all mammalian cells? Nucleus 2011, 2:562-569.

62. Kim Y, Sharov AA, McDole K, Cheng M, Hao H, Fan CM, Gaiano N, Ko MS Zheng $Y$ : Mouse B-type lamins are required for proper organogenesis but not by embryonic stem cells. Science 2011, 334:1706-1710.

63. Pickersgill H, Kalverda B, de Wit E, Talhout W, Fornerod M, van Steensel B: Characterization of the Drosophila melanogaster genome at the nuclear lamina. Nat Genet 2006, 38:1005-1014.

64. Guelen L, Pagie L, Brasset E, Meuleman W, Faza MB, Talhout W, Eussen BH, de Klein A, Wessels L, de Laat W, van Steensel B: Domain organization of 
human chromosomes revealed by mapping of nuclear lamina interactions. Nature 2008, 453:948-951.

65. Towbin BD, Meister P, Gasser SM: The nuclear envelope-a scaffold for silencing? Curr Opin Genet Dev 2009, 19:180-186.

66. Peric-Hupkes D, Meuleman W, Pagie L, Bruggeman SW, Solovei I, Brugman W, Graf S, Flicek P, Kerkhoven RM, van Lohuizen M, et al: Molecular maps of the reorganization of genome-nuclear lamina interactions during differentiation. Mol Cell 2010, 38:603-613.

67. Chen $H$, Chen $X$, Zheng $Y$ : The nuclear lamina regulates germline stem cell niche organization via modulation of EGFR signaling. Cell Stem Cell 2013, 13:73-86.

68. Coffinier C, Chang SY, Nobumori C, Tu Y, Farber EA, Toth Jl, Fong LG, Young SG: Abnormal development of the cerebral cortex and cerebellum in the setting of lamin B2 deficiency. Proc Natl Acad Sci USA 2010, 107:5076-5081.

69. Coffinier C, Fong LG, Young SG: LINCing lamin B2 to neuronal migration: growing evidence for cell-specific roles of B-type lamins. Nucleus 2010, 1:407-411.

70. Ji JY, Lee RT, Vergnes L, Fong LG, Stewart CL, Reue K, Young SG, Zhang Q, Shanahan CM, Lammerding J: Cell nuclei spin in the absence of lamin b1. J Biol Chem 2007, 282:20015-20026.

71. Tsai MY, Wang S, Heidinger JM, Shumaker DK, Adam SA, Goldman RD, Zheng Y: A mitotic lamin B matrix induced by RanGTP required for spindle assembly. Science 2006, 311:1887-1893.

72. Stuurman N, Heins S, Aebi U: Nuclear lamins: their structure, assembly, and interactions. J Struct Biol 1998, 122:42-66.

73. Jung HJ, Nobumori C, Goulbourne CN, Tu Y, Lee JM, Tatar A, Wu D, Yoshinaga Y, de Jong PJ, Coffinier C, et al: Farnesylation of lamin B1 is important for retention of nuclear chromatin during neuronal migration. Proc Natl Acad Sci USA 2013, 110:E1923-E1932.

74. Prufert K, Vogel A, Krohne G: The lamin CxxM motif promotes nuclear membrane growth. J Cell Sci 2004, 117:6105-6116.

75. Ralle T, Grund C, Franke WW, Stick R: Intranuclear membrane structure formations by CaaX-containing nuclear proteins. J Cell Sci 2004, 117:6095-6104.

76. Heng MY, Lin ST, Verret L, Huang Y, Kamiya S, Padiath QS, Tong Y, Palop Jر, Huang EJ, Ptacek LJ, Fu YH: Lamin B1 mediates cell-autonomous neuropathology in a leukodystrophy mouse model. J Clin Invest 2013, 123:2719-2729.

77. Malhas AN, Lee CF, Vaux DJ: Lamin B1 controls oxidative stress responses via Oct-1. J Cell Biol 2009, 184:45-55.

78. Columbaro M, Mattioli E, Maraldi NM, Ortolani M, Gasparini L, D'Apice MR, Postorivo D, Nardone AM, Avnet S, Cortelli P, et al: Oct-1 recruitment to the nuclear envelope in adult-onset autosomal dominant leukodystrophy. Biochim Biophys Acta 1832, 2013:411-420.

79. Xu N, Papagiannakopoulos T, Pan G, Thomson JA, Kosik KS: MicroRNA-145 regulates OCT4, SOX2, and KLF4 and represses pluripotency in human embryonic stem cells. Cell 2009, 137:647-658.

80. Bartel DP: MicroRNAs: genomics, biogenesis, mechanism, and function. Cell 2004, 116:281-297.

81. Esteller M: Non-coding RNAs in human disease. Nat Rev Genet 2011, 12:861-874

82. Qureshi IA, Mehler MF: Emerging roles of non-coding RNAs in brain evolution development, plasticity and disease. Nat Rev Neurosci 2012, 13:528-541.

83. Pauli A, Rinn JL, Schier AF: Non-coding RNAs as regulators of embryogenesis. Nat Rev Genet 2011, 12:136-149.

84. Lewis BP, Burge CB, Bartel DP: Conserved seed pairing, often flanked by adenosines, indicates that thousands of human genes are microRNA targets. Cell 2005, 120:15-20.

85. Lau P, Verrier JD, Nielsen JA, Johnson KR, Notterpek L, Hudson LD: Identification of dynamically regulated microRNA and mRNA networks in developing oligodendrocytes. J Neurosci 2008, 28:11720-11730.

86. Budde H, Schmitt S, Fitzner D, Opitz L, Salinas-Riester G, Simons M: Control of oligodendroglial cell number by the miR-17-92 cluster. Development 2010, 137:2127-2132.

87. Dugas JC, Cuellar TL, Scholze A, Ason B, lbrahim A, Emery B, Zamanian JL, Foo LC, McManus MT, Barres BA: Dicer1 and miR-219 Are required for normal oligodendrocyte differentiation and myelination. Neuron 2010, 65:597-611.

88. Zhao X, He X, Han X, Yu Y, Ye F, Chen Y, Hoang T, Xu X, Mi QS, Xin M, et al: MicroRNA-mediated control of oligodendrocyte differentiation. Neuron 2010, 65:612-626.
89. Dugas JC, Notterpek L: MicroRNAs in oligodendrocyte and Schwann cell differentiation. Dev Neurosci 2011, 33:14-20.

90. Shin S, Cha HJ, Lee EM, Jung JH, Lee SJ, Park IC, Jin YW, An S: MicroRNAs are significantly influenced by p53 and radiation in HCT116 human colon carcinoma cells. Int J Oncol 2009, 34:1645-1652.

91. Lin ST, Huang Y, Zhang L, Heng MY, Ptacek LJ, Fu YH: MicroRNA-23a promotes myelination in the central nervous system. Proc Natl Acad Sci USA 2013, 110:17468-17473.

92. Orom UA, Derrien T, Beringer M, Gumireddy K, Gardini A, Bussotti G, Lai F, Zytnicki M, Notredame C, Huang Q, et al: Long noncoding RNAs with enhancer-like function in human cells. Cell 2010, 143:46-58.

93. Berndt JA, Kim JG, Tosic M, Kim C, Hudson LD: The transcriptional regulator Yin Yang 1 activates the myelin PLP gene. J Neurochem 2001, 77:935-942.

94. Mercer TR, Qureshi IA, Gokhan S, Dinger ME, Li G, Mattick JS, Mehler MF: Long noncoding RNAs in neuronal-glial fate specification and oligodendrocyte lineage maturation. BMC Neurosci 2010, 11:14.

95. Inoue K, Osaka H, Sugiyama N, Kawanishi C, Onishi H, Nezu A, Kimura K, Yamada Y, Kosaka K: A duplicated PLP gene causing Pelizaeus-Merzbacher disease detected by comparative multiplex PCR. Am J Hum Genet 1996, 59:32-39.

96. Inoue K: PLP1-related inherited dysmyelinating disorders: PelizaeusMerzbacher disease and spastic paraplegia type 2. Neurogenetics 2005, 6:1-16.

97. Bauer J, Bradl M, Klein M, Leisser M, Deckwerth TL, Wekerle H, Lassmann H: Endoplasmic reticulum stress in PLP-overexpressing transgenic rats: gray matter oligodendrocytes are more vulnerable than white matter oligodendrocytes. J Neuropathol Exp Neurol 2002, 61:12-22.

doi:10.1186/2047-9158-3-4

Cite this article as: Lin et al:: Regulation of Myelination in the Central Nervous System by Nuclear Lamin B1 and Non-coding RNAs.

Translational Neurodegeneration 2014 3:4.

\section{Submit your next manuscript to BioMed Central and take full advantage of:}

- Convenient online submission

- Thorough peer review

- No space constraints or color figure charges

- Immediate publication on acceptance

- Inclusion in PubMed, CAS, Scopus and Google Scholar

- Research which is freely available for redistribution 